\title{
Identifikasi Tegangan pada Permukaan Karet SBR-25 saat mengalami Kontak Abrasi: Investigasi Numerik
}

\author{
B. Setiyana, J. Jamari, I. Haryanto, M. Munadi
}

Departemen Teknik Mesin, Universitas Diponegoro

Jl. Prof. Sudharto, SH.,Tembalang, Semarang, 50275

Email korespondensi: bsetiyana@yahoo.com

\begin{abstract}
Abstrak
Keausan akibat abrasi pada komponen yang terbuat dari material karet seperti pada ban kendaraan atau seal sangat menentukan umur pakai dari komponen tersebut. Dalam material karet, ketika permukaan yang masih halus mengalami abrasi, maka akan terbentuk permukaan yang bergerigi secara paralel yang arahnya tegak lurus dengan arah gerak abrasi. Bentuk permukaan yang bergerigi ini akan terus menerus terbentuk selama proses kontak abrasi masih berjalan. Keausan abrasi terjadi akibat tegangan pada material karet melampaui tegangan patah material. Tetapi analisis keausan abrasi pada karet masih sangat sulit dilakukan secara analitik dikarenakan sifat karet yang non linier dan hyperelastic. Dengan menggunakan metoda numerik, tulisan ini membahas tegangan yang terjadi pada permukaan karet SBR-25 yang sudah terabrasi. Sebagai studi awal, analisis dilakukan dalam dua dimensi dengan menggunakan perangkat lunak komersial ABAQUS 6.14-5 dengan memodelkan karet yang kontak dengan indenter yang kaku. Simulasi dilakukan dengan variasi kedalaman indentasi, kekasaran permukaan dan dimensi gigi (chip). Secara umum hasil menunjukkan bahwa makin besar kedalaman indentasi dan kekasaran permukaaan akan meningkatkan nilai tegangan maksimum. Disisi lain, lokasi terjadinya tegangan maksimum (tegangan kritis) juga sangat dipengaruhi oleh kedalaman indentasi, kekasaran permukaan dan dimensi dari chip.
\end{abstract}

Kata kunci: abrasi, chip, hyperelastic, indenter.

\begin{abstract}
Wear due to abrasion on components made of rubber-like material such as on a vehicle tire or seal strongly determines the service life of these components. In rubber material, when the surface is still smooth experiencing abrasion contact, it will form a ridge shaped on abraded surface in a parallel direction perpendicular to the direction of motion of the abrasion. The ridge shaped of the abraded surface will be continuously formed during the abrasion process. Abrasion wear occurs due to stress on the rubber material beyond the fracture stress of the material. However, the analysis of abrasion wear on rubber is still very difficult to discuss analytically due to the non-linear and hyper-elastic properties of rubber material. Using a numerical method, this paper discusses the stresses that occur on the abraded rubber surfaces of SBR-25. As a preliminary study, the analysis was carried out in two dimensions using commercial software ABAQUS 6.14-5 by modeling the rubber in contact with a single rigid indenter. Simulations are carried out with variations in indentation depth, surface roughness and ridge (chip) dimensions. In general, the results show that the large indentation depth and surface roughness increase the maximum stress value. On the other hand, the location of the maximum stress (critical stress) is also strongly influenced by indentation depth, surface roughness and dimensions of the chip.
\end{abstract}

Keywords: adhesion, chip, hyper-elastic, indentor

\section{Pendahuluan}

Sebuah material ketika menerima beban luar, baik beban berupa gaya, tekanan, ataupun regangan akan menunjukkan respon yang berbeda-beda antara material satu dengan yang lainnya. Penyebabnya, tidak lain adalah perbedaan sifat tiap material itu sendiri. Dalam analisis kontak gesek secara umum, material karet bersifat lebih lunak dari material penggoresnya (indenter). Secara umum koefisien gesek pada kontak gesek pada material hyperelastic swpwerti pada material karet terdiri dari dua komponen, yaitu komponen adhesi yang disebabkan oleh kekasaran permukaan dan komponen hysteresis yang disebabkan oleh deformasi permukaan material. Kekasaran permukaan ini sudah biasa dikaitkan dengan koefisien gesek pada material logam atau material kaku lainnya. Tetapi pada material karet, sifat yang mudah berubah bentuk atau terdeformasi akan memberikan kontribusi yang cukup dominan pada koefisien gesek total. Fenomena ini memunculkan koefisien gesek akibat deformasi atau hysteresis [1-2].

Dalam material karet, ketika permukaan yang masih halus mengalami abrasi, maka akan terbentuk permukaan yang bergerigi secara paralel yang 
arahnya tegak lurus dengan arah gerak abrasi. Bentuk permukaan yang bergerigi ini akan terbentuk selama dan setelah proses kontak abrasi berjalan [3-7]. Gambar 1(a) menampilkan pandangan atas permukaan terabrasi dari karet dan Gambar 1(b) adalah pandangan depan permukaan dengan menampilkan beberapa chip atau geram dari permukaan yang bergerigi karena abrasi. Keausan abrasi terjadi akibat tegangan yang terjadi pada material karet melampaui tegangan patah material. Secara logika, peristiwa patah dan lepasnya material dimulai dari tegangan maksimum yang timbul [8-9].

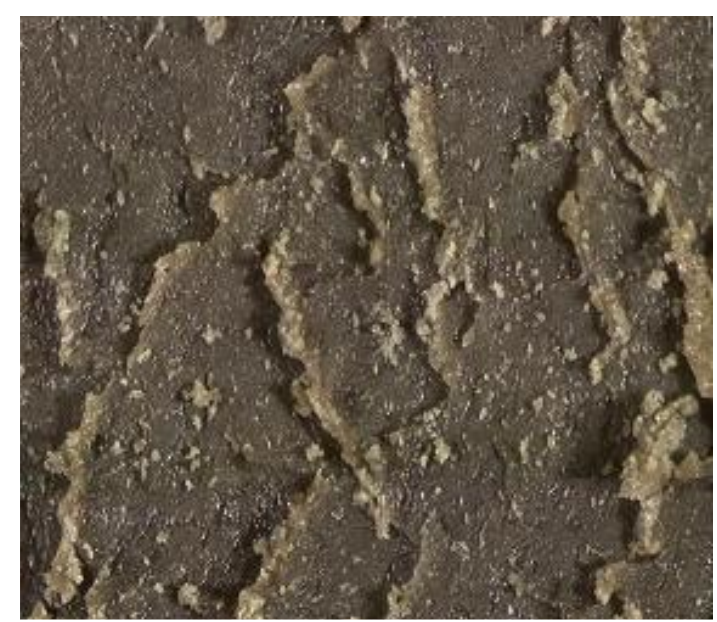

(a)

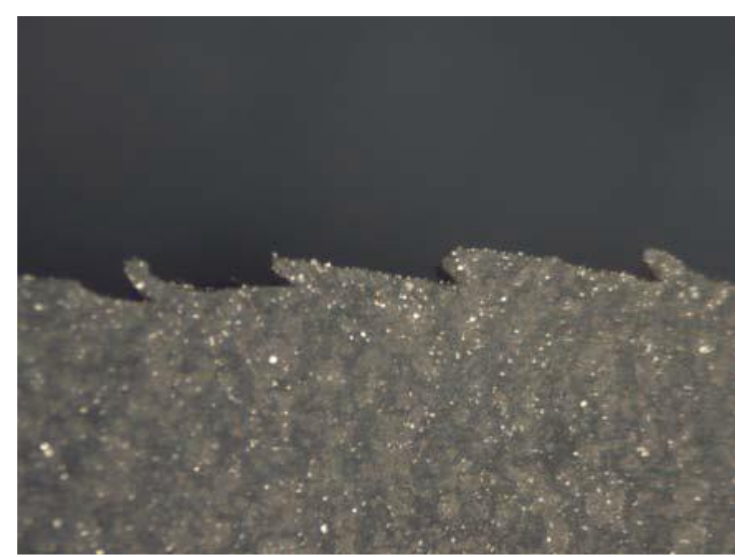

(b)

Gambar 1. Bentuk permukaan karet yang terabrasi berupa permukaan yang bergerigi dari (a) pandangan atas dan (b) pandangan samping

Penelitian ini dilakukan terhadap kasus kontak abrasi antara material karet atau elastomer dengan indenter kaku. Ini dilakukan sebagai studi awal untuk mempelajari fenomena abrasi. Jenis karet yang dianalisis adalah Styrene-butadiene Rubber (SBR-25) dengan rigid blade indenter, dimana permukaan elastomer dalam kondisi yang sudah terabrasi. Karet SBR-25 ini merupakan karet kompon yang dipadu dengan karbon hitam. Tetapi karena sifat mekanis yang unik, menjadikan analisis karet sangat sulit dilakukan secara analitik dikarenakan sifat karet yang non linier dan hyperelastic. Penggunaan blade atau pisau sebagai indenter sering dipakai oleh peneliti karena bentuk kontaknya dianggap berupa garis lurus dan indenter jenis ini merupakan indenter sederhana yang dapat memberikan laju keausan, yaitu volume material karet yang aus atau lepas [10-11].

Dengan menggunakan metoda numerik berbasis Finite Element (FE), tulisan ini membahas tegangan yang terjadi pada permukaan karet yang sudah terabrasi. Tetapi dalam melakukan simulasi numerik, tetap dibutuhkan data hubungan antara tegangan dan regangan yang didapat dari hasil uji tarik berupa Strain Energy Function (SEF). Konstanta yang ada di data SEF ini digunakan sebagai data masukan untuk melakukan simulasi numerik pada bagian data sifatsifat material. Hasil final dari penelitian ini adalah distribusi tegangan saat melakukan kontak abrasi beserta lokasi tegangan maksimum atau tegangan kritisnya.

\section{Metode}

Gambaran kasus dari penelitian ini dimodelkan dalam bentuk 2 dimensi (plane strain) dengan geometri yang dijelaskan pada Gambar 2(a). Ini merupakan skema pemodelan untuk Finite Element dan meshing yang terjadi dari karet atau elastomers dimana elastomers tersebut diibaratkan memiliki permukaan yang sudah terabrasi dengan permukaan yang bergerigi. Untuk menyederhanakan simulasi, pada permukaan karet ini diberikan sebuah gerigi atau geram (chip) dengan dimensi tertentu. Panjang spesimen elastomers 20 $\mathrm{mm}$, lebar dari elastomers $10 \mathrm{~mm}$ dan radius blade indenter disimbolkan dengan r. Sisi kanan dan kiri elastomer ditumpu pada arah horizontal dan dapat bergerak bebas arah vertikal, sedangkan bagian bawah elastomer ditumpu mati.

Bentuk chip merupakan perwakilan gigi pada permukaan karet yang terabrasi. Disini diberikan satu buah chip sebagai model dengan dimensi yang tertentu. Secara umum ada hubungan antara $\mathrm{h}_{1}, \mathrm{~h}_{2}$ dan sudut $\theta$ dari dimensi chip tersebut, tergantung jenis material karetnya [2]. Pada tulisan ini, nilai konstanta dari SEF untuk material SBR-25 ditentukan berdasarkan hasil uji tarik oleh yang dilakukan oleh Liang [3] dan didapat hubungan tegangan-regangan untuk karet SBR-25 berupa data SEF. Banyak peneliti yang membuat model untuk SEF dan SEF pada penelitian ini adalah model Yeoh [3].

Penelitian ini dilakukan untuk beberapa ketebalan chip $\left(\mathrm{h}_{1}\right)$ yaitu $0,3 \mathrm{~mm}, 0,4 \mathrm{~mm}$ dan 0,6 . Penelitian juga dilakukan untuk beberapa kedalaman indentasi yaitu $0,5 \mathrm{~mm}, 1,0 \mathrm{~mm}$ dan $1,0 \mathrm{~mm}$. Setelah dilakukan indentasi, kemudian memberikan perpindahan indenter pada arah horizontal sejauh $8 \mathrm{~mm}$. Adapun kekasaran permukaan kontak dalam penelitian ini dinyatakan dengan koefisien gesek adhesi, yang 
diberikan nilai 0 untuk permukaan halus dan 0,5 untuk permukaan kasar.

Penyelesaian kasus indentasi ini dilakukan menggunakan metode elemen hingga dengan bantuan software Abaqus 6.14-5. Ini merupakan salah satu software metode elemen hingga yang populer digunakan. Selain itu software Abaqus 6.14-5 menyediakan fasilitas analisa non-linier untuk mekanika kontak.

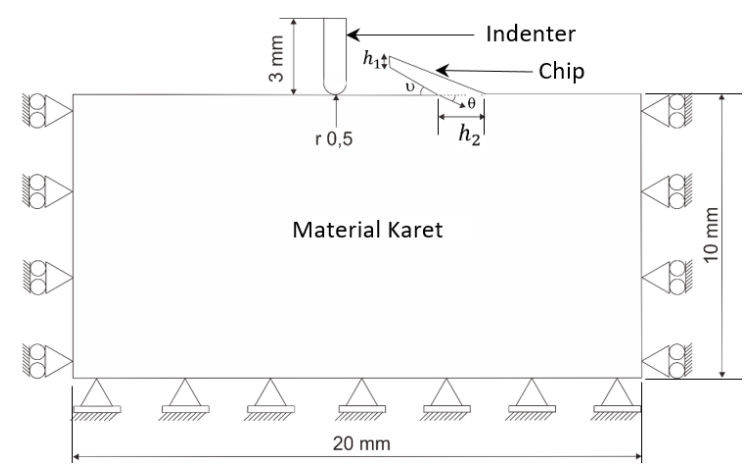

(a)

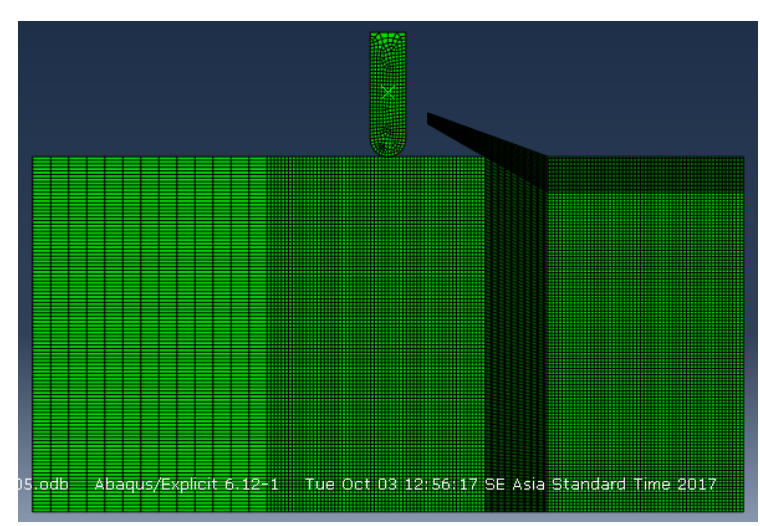

(b)

Gambar 2. Pemodelan awal kontak gesek antara indenter dengan permukaan karet yang bergerigi

(a) Sketsa pemodelan dan (b) Meshing pada spesimen dan indenter.

Gambar 2(b) merupakan tampilan dari model FE setelah mengalami meshing, baik untuk spesimen maupun untuk indenternya. Pada bagian sekitar chip, dibuat mesh yang lebih halus, agar hasil distribusi tegangan dari simulasi ditampilkan lebih akurat. Hasil yang didapat dari penelitian ini yaitu distribusi tegangan di sekitar area kontak dan lokasi tegangan kritis atau tegangan maksimum.

\section{Hasil dan Pembahasan}

Pada pemodelan yang penulis buat total simulasi yang telah berhasil dilakukan dengan beberapa variasi kedalaman indentasi, ketebalan chip, koefisien gesek adhesi. Gambar 3 menampilkan deformasi dan distribusi tegangan untuk permukaan karet disekitar chip (gerigi) saat chip tertabrak oleh indenter dengan variasi kekasaran, yaitu koefisien gesek adhesi 0 dan 0,5 . Dari gambar terlihat bahwa permukaan yang kasar, yaitu koefisien adhesi 0,5 akan memberikan tegangan yang lebih besar (4,093 Mpa) dibanding yang halus (1,248 Mpa). Secara umum, tegangan maksimum berlokasi disekitar ujung indenter.

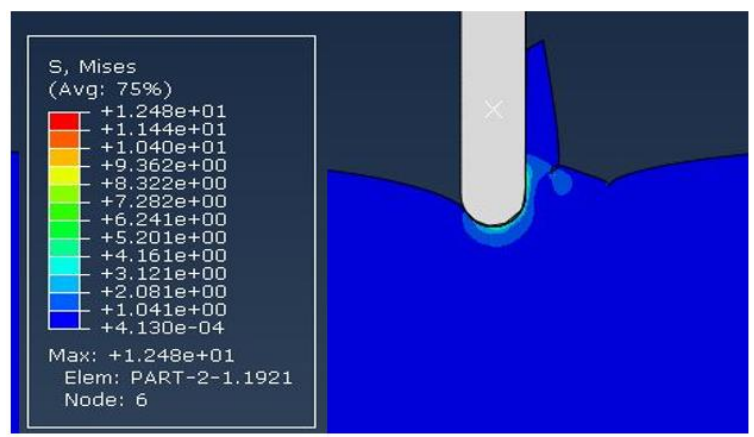

(a)

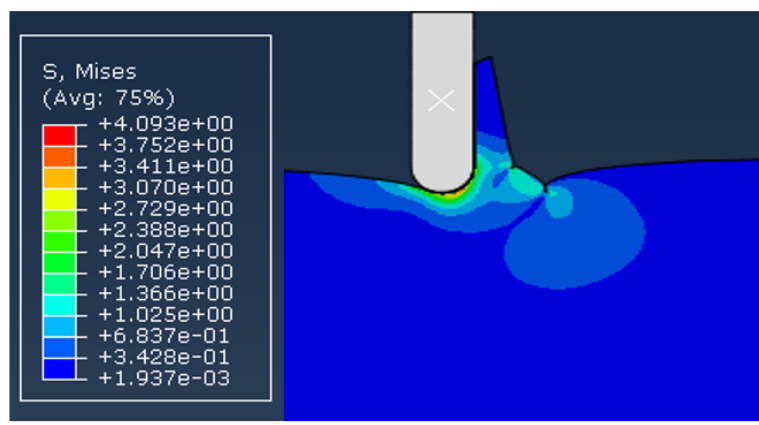

(b)

Gambar 3. Distribusi tegangan untuk ketebalan chip 0,3 $\mathrm{mm}$ dan kedalaman indentasi 1,0 $\mathrm{mm}$ pada koefisien gesek adhesi (a) 0 dan (b) 0,5.

Dalam penelitian ini dikenalkan dengan titik kritis, yaitu merupakan lokasi tegangan maksimum yang dinyatakan dengan sudut kritis. Sudut kritis diukur dari garis horizontal sisi depan indenter terhadap titik pusat lingkaran dari ujung indenter. Lokasi titik kritis merupakan lokasi tegangan maksimum yang kemungkinan besar awal retak akibat abrasi terjadi di lokasi ini jika tegangan ini melampaui tegangan patah dari material karet.

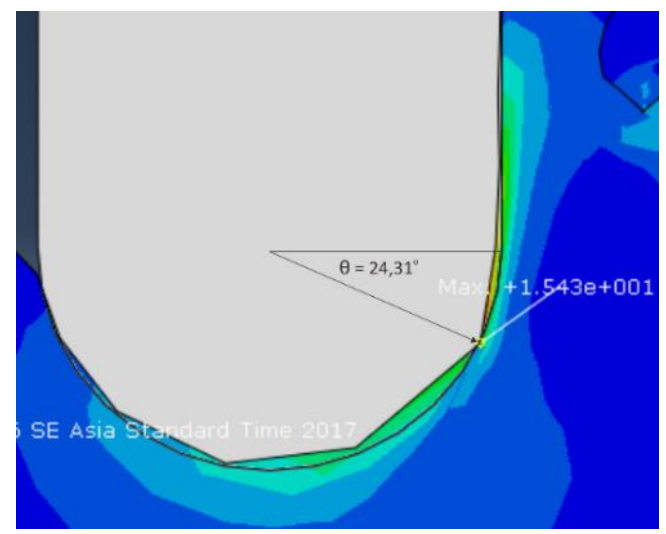

(a) 


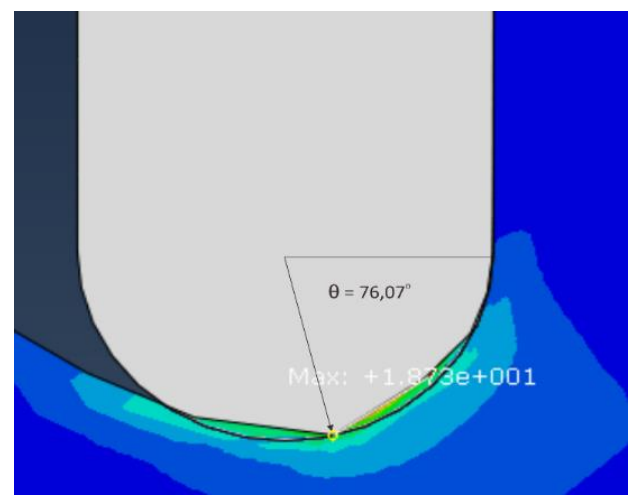

(b)

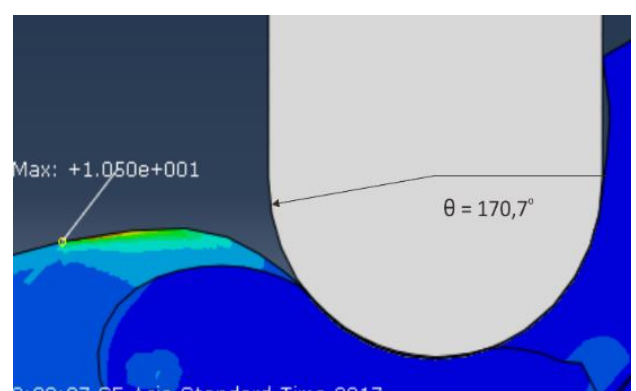

(c)

Gambar 4. Posisi tegangan kritis untuk koefisien gesek adhesi 0 dan ketebalan chip 0,3 untuk kedalaman (a) 0,5 $\mathrm{mm}$ (b) $1,0 \mathrm{~mm}$ dan (c) $1,5 \mathrm{~mm}$

Lokasi tegangan kritis atau tegangan maksimum untuk variasi kedalam indentasi pada permukaan yang halus diberikan pada gambar 4. Simulasi dilakukan untuk ketebalan chip $0,3 \mathrm{~mm}$. Terlihat bahwa pada kedalaman indentasi $0,5 \mathrm{~mm}$, lokasi titik kritis berada didepan indenter membentuk sudut $24,31^{\circ}$, tetapi sudut ini meningkat seiring dengan pertambahan kedalaman indentasi. Untuk indentasi 1,5 mm, sudut kritis yang terbentuk adalah $170,7^{\circ}$ dan berada dibelakang indenter.

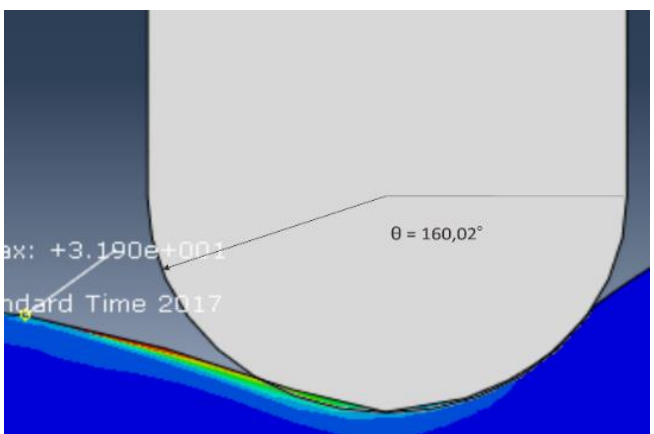

Gambar 5. Posisi tegangan kritis untuk kedalaman indentasi $1,0 \mathrm{~mm}$ dan ketebalan chip $0,3 \mathrm{~mm}$ pada koefisien gesek adhesi 0,5 .

Lokasi tegangan kritis untuk permukaan yang kasar, yaitu dengan koefisien adhesi 0,5 akan memberikan perubahan sudut dibanding yang permukaan halus. Gambar 5 memberikan data tentang sudut kritis tersebut yaitu sebesar $160,02^{\circ}$ yang nilainya lebih besar dibanding permukaan yang halus seperti di gambar 3(b), yaitu sebesar $76,07^{\circ}$. Pergeseran lokasi titik kritis ini disebabkan oleh kontak stick antar indenter dengan permukaan kasar, dimana akibat kontak tersebut indenter dan permukaan karet bergerak menyatu, sehingga bagian karet dibelakang indenter mengalami tegangan tarik yang besar. Tegangan tarik inilah yang memunculkan terjadinya tegangan maksimum.

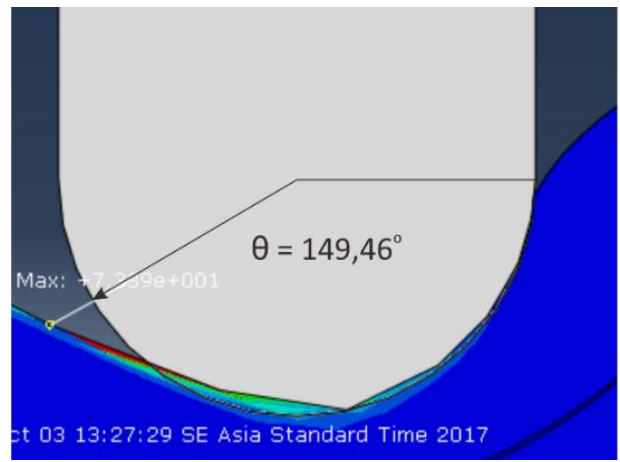

(a)

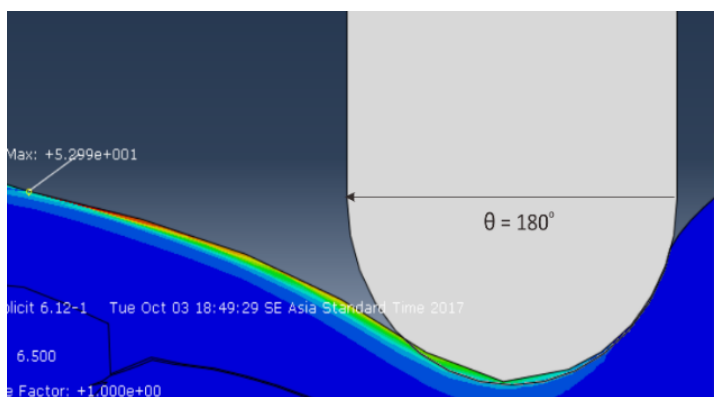

(b)

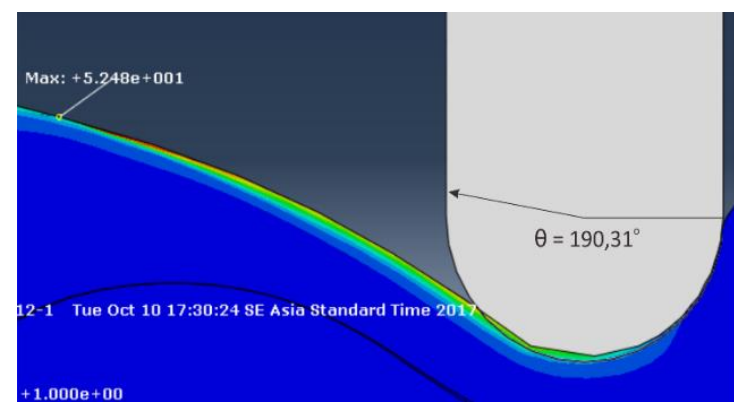

(c)

Gambar 6. Posisi tegangan kritis untuk koefisien gesek adhesi 0,5 dan kedalaman indentasi 1,0 $\mathrm{mm}$ untuk tebal chip (a) $0,3 \mathrm{~mm}$ (b) $0,4 \mathrm{~mm}$ dan (c) $0,5 \mathrm{~mm}$

Gambar 6 menunjukkan perubahan lokasi titik kritis berdasar variasi ketebalan chip, yaitu 0,3 mm, 0,4 mm dan 0,5 mm. Dari gambar terlihat bahwa makin tebal chip akan memberikan sudut kritis yang lebih besar. Dengan kedalaman indentasi yang sama, chip yang lebih tebal akan menjadikan indenter menekan lebih dalam saat indenter persis diatas badan chip. Sehingga kedalaman total sebesar kedalaman indentasi ditambah ketebalan chip. Konsekuensinya, lokasi titik kritis untuk chip yang tebal lebih tinggi dan sudutnya menjadi besar. 
Gambar 7 memperlihatkan hubungan tegangan maksimum dengan perpindahan indenter dengan variasi kedalaman indentasi. Secara umum terlihat adanya fluktuasi tegangan saat indenter bergeser sejauh 4 sampai $8 \mathrm{~mm}$. Untuk kedalaman 1,0 $\mathrm{mm}$ dan 1,5 mm, simulasi menghasilkan tegangan maksimum yang relatif sama, tetapi respon yang lebih lambat diberikan oleh kedalaman yang $1,5 \mathrm{~mm}$. Ini terjadi saat indenter mulai menabrak chip sampai lepas kontak dari chip. Fenomena fluktuasi ini sering disebut stick-slip [12-14]. Stick terjadi ketika material elastomers menempel pada permukaan indenter, menyatu dengan gerakan indenter sehingga mengakibatkan nilai tegangan maksimum yang membesar. Tegangan maksimum terbesar terjadi pada saat indenter mengenai chip yang mewakili bentuk permukaan elastomers yang sudah terabrasi. Oleh sebab itu fenomena stick-slip terbesar terjadi saat kontak antara indenter dengan chip. Dan ketika slip terjadi, material elastomers lepas dari permukaan indenter dan nilai tegangan langsung akan mengecil. Fenomena stick-slip ini terjadi dengan cepat dan berulang sehingga terlihat nilai tegangan maksimum yang fluktuatif. Dan untuk diketahui bahwa fenomena stick-slip adalah fenomena yang umum terjadi pada kontak gesek dengan permukaan karet [13].

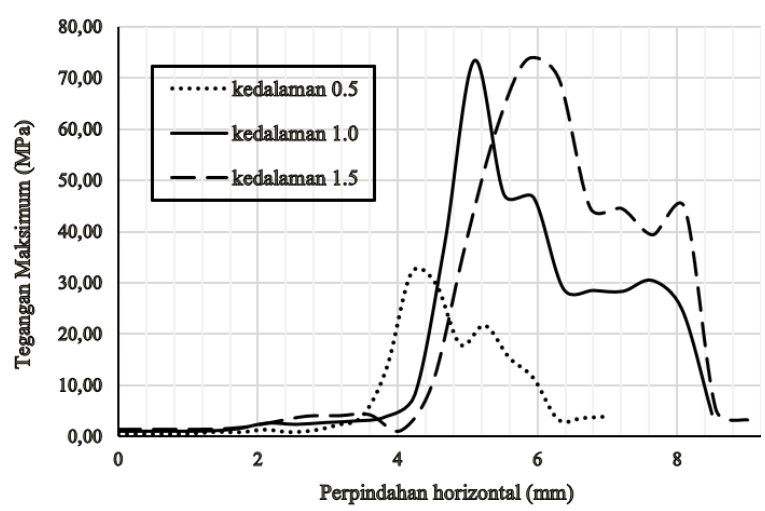

Gambar 7. Tegangan maksimum karet untuk ketebalan chip $0,3 \mathrm{~mm}$ dan koefisien gesek adhesi 0,5 pada variasi kedalaman indentasi

Pemodelan dengan variasi ketebalan chip pada elastomers dengan kedalaman indentasi $1,0 \mathrm{~mm}$, koefisien gesek adhesi 0,5 diberikan pada Gambar 8 . Pemodelan dengan variasi ketebalan chip sebesar 0,6 mm menghasilkan nilai tegangan maksimal yang yang lebih tinggi di bandingkan dengan ketebalan chip 0,3 $\mathrm{mm}$ dan $0,4 \mathrm{~mm}$. Yang menarik adalah nilai tegangan maksimum untuk ketebalan chip $0,3 \mathrm{~mm}$ dan $0,4 \mathrm{~mm}$, dimana nilai tegangan puncak untuk tebal chip 0,3 $\mathrm{mm}$ lebih besar dari tebal chip $0,4 \mathrm{~mm}$, tetapi tegangan puncak untuk tebal chip $0,3 \mathrm{~mm}$ mempunyai rentang yang lebih pendek dibanding yang untuk tebal chip 0,4 mm. Tetapi pada prinsipnya, tegangan maksimum untuk ketiga tebal chip mulai membesar pada saat yang sama, yaitu saat indenter bergeser di sekitar 4,2 mm.

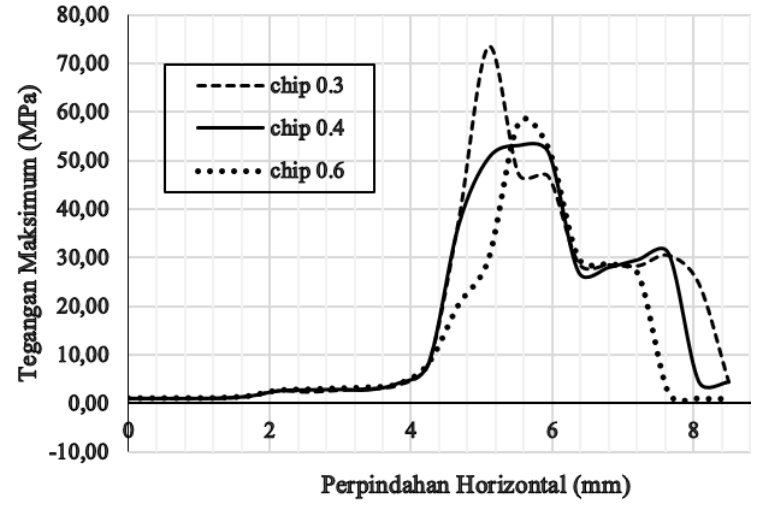

Gambar 8. Tegangan maksimum untuk kedalaman indentasi $1,0 \mathrm{~mm}$ dan koefisien gesek adhesi 0,5 pada variasi ketebalan chip.

Berdasar hasil simulasi diatas dapat disimpulkan bahwa besar tegangan yang terjadi tergantung pada kedalaman indentasi, kekasaran permukaan kontak dan ketebalan chip. Makin dalam indentasi secara umum akan meningkatkan tegangan yang terjadi, demikian juga dengan meningkatnya kekasaran permukaan dan ketebalan chip. Lokasi titik kritis yang merupakan lokasi tegangan maksimum dinyatakan dengan sudut kritis. Sudut kritis diukur dari garis horizontal sisi depan indenter terhadap titik pusat lingkaran dari ujung indenter. Makin besar kedalaman indentasi dan makin besar tingkat kekasaran permukaan kontak akan meningkatkan sudut kritis.

Terlihat grafik yang fluktuatif berkaitan dengan hubungan antara tegangan maksimum dan pergeseran indenter, hal ini dikarenakan adanya fenomena stickslip. Stick terjadi ketika material elastomers menempel pada permukaan indenter, menyatu dengan gerakan indenter sehingga mengakibatkan nilai koefisien gesek deformasi (hysteresis) semakin besar dan tegangan maksimum juga makin besar. Dan ketika slip terjadi, material elastomers lepas dari permukaan indenter dan nilai koefisien gesek deformasi akan mengecil, sehingga tegangan maksimum juga langsung mengecil.

\section{Kesimpulan}

Kajian mengenai kontak material karet yang bersifat hyperelastic menggunakan metode elemen hingga ini telah menunjukkan karakteristik material hyperelastic ketika terjadi kontak. Dari hasil simulasi variasi kedalaman indentasi blade indenter dapat menghasilkan beberapa output diantaranya distribusi tegangan maksimal dan lokasi terjadinya tegangan maksimum yang dinyatakan dengan sudut kritis. Dari serangkaian hasil simulasi tersebut didapatkan beberapa kesimpulan, antara lain:

1. Tegangan material karet saat kontak abrasi sangat dipengaruhi oleh kedalaman indentasi, kekasaran permukaan kontak dan ketebalan chip 
2. Peningkatan kedalaman indentasi dan kekasaran permukaan akan meningkatkan nilai tegangan dan sudut kritis

3. Peningkatan tebal chip juga akan membuat sudut kritis menjadi besar. Chip yang tebal akan membuat kedalaman indentasi total juga besar

4. Tegangan yang fluktuatif muncul saat indenter bergeser dan melewati chip. Ini disebabkan oleh efek deformasi yang sering disebut efek hysteresis

\section{Daftar Pustaka}

[1] K. L. Johnson. 1985, "Contact Mechanics." 9th edition, University of Cambridge.

[2] A. N. Gent. 1992, "Engineering with Rubber, How to design rubber components." 3rd edition, Hanser Publication, Cincinati, ISBN 978-3-44642764-8.

[3] H. Liang, Y. Fukahori, A.G. Thomas, J.J.C. Busfield. 2009, "Rubber abrasion at steady state." Wear, Vol. 266, 288-296.

[4] Y. Fukahori and H. Yamazaki. 1994, "Mechanism of rubber abrasion - Part 2: General rule in abrasion pattern formation in rubber-like materials." Wear, Vol. 178, 109-116.

[5] Y. Uchiyama and Y. Ishino. 1992, "Pattern abrasion mechanism of rubber." Wear, Vol. 158, 141-155.

[6] B. Setiyana, R. Ismail, J. Jamari and D. J. Schipper. 2018, "Analytical Study of the wear pattern of an abraded rubber surface: Interaction Model." Tribology, Material Surface and Interfaces, Vol. 1, 1-7.

[7] M. Khafidh, B. Setiyana, J. Jamari, M. Masen, D.J. Schipper. 2018, "Understanding the occurrence of wavy track of elastomeric material." Wear, Vol. 412-413, 23-29.

[8] C. T. Mc. Carthy, A.N Annaidh, M. D. Gilchrist. 2010, "On the sharpness of straight edge blades in cutting soft solids: Part II - analysis of blade geometry." Engineering Fracture Mechanics, Vol. 77, 437-451.

[9] B. Setiyana, R. Ismail, J. Jamari and D. J. Schipper. 2017, “A Numerical Investigation of Mechanical Behavior of Unfilled Styrene Butadiene Rubber by Static Straight Blade Indentation." Journal of Mechanical Engineering, SI 1 (1), 45-5.

[10] S. W. Zhang. 2004, "Tribology of Elastomer." Tribology and Interface Engineering Series, Elsevier, Amsterdam.

[11] V. Coveney and C. Menger. 1999, "Initiation and development of wear of an elastomeric surface by a blade abrader." Wear, Vol. 233-235, 702711.

[12] T. Vieira, R. P. Ferreira, A. K. Kuchiishi, L. L. B. Bernucci, A. Sinatora. 2015, "Evaluation of friction mechanisms and wear rates on rubber tire materials by low-cost laboratory tests." Wear, Vol. 328-329, 556-562.
[13] B. Setiyana, R. Ismail, J. Jamari and D. J. Schipper. 2016, "Stick-Slip Behaviour of a Viscoelastic Flat Sliding Along a Rigid Indenter." Tribology Online, Vol. 11,3, 512-518.

[14] Y.P. Wu, Y. Zhou, J.L. Li, H.D. Zhou, J.M. Chen, H.C. Zhao. 2016, "A comparative study on wear behavior and mechanism of styrene butadiene rubber under dry and wet conditions." Wear, Vol. 356-357,1-8. 